\title{
The Research of the Effect of Barrier Layer on the Development of Bottom Water Reservoirs in Streamline Simulation
}

\author{
Ding Jie ${ }^{1, a}$, Mingxian Wang ${ }^{1, b}$, Wanjing Luo ${ }^{1, c}$ \\ ${ }^{1}$ School of Energy Resources, China University of Geosciences (Beijing), Beijing, 100083, China \\ ading_colin@163.com, ’bangmingxian89@126.com, 'luowanjing@vip.qq.com
}

Keywords: Bottom water reservoir, Barrier layer, Bottom water coning, Streamline simulation.

Abstract. Bottom water coning is the main problem in the development of bottom water reservoirs and barrier layer in these reservoirs can control bottom water coning in some degree, so the research of the effect of barrier layer in bottom water reservoirs is carried out. This paper, in streamline simulation method, established a model of a bottom water reservoir with a horizontal well and analyzed the effect of the barrier layer on the development of bottom water reservoirs, respectively, from three aspects of the barrier layer: the permeability, the size and the spatial distribution. The results show that: the barrier layer can control the bottom water coning and improve the development effect of bottom water reservoirs. Under the same production condition, the lower permeability of the barrier layer ,the larger size of the barrier layer and the closer distance between the barrier layer and the top of the horizontal segment is, the better the development effect is. When there are multiple barrier layers and the barrier layers just move at the same height, the development effect is the same.

\section{Introduction}

Oil reservoirs with bottom water drive are widely distributed in China, which have high oil recovery due to supplemental energy from the aquifer[1]. However, when the oil production rate exceeds critical rate, water is also produced due to the upwards invasion of the oil-water contact known as water coning, which is the main problem in the development of these reservoirs[2]. After the bottom water breakthrough, the well would be shut down because of the uneconomic oil production rate[3]. With the purpose of removing unwanted water in oil production, a few methods have been studied as applied in oilfields: perforating far away from the original oil-water contact[4]; producing oil below the critical rate[5]; injecting oil back to the reservoir[6]; injecting polymers or gels to form a barrier between oil and water zones[7]; using horizontal wells[8]; producing oil and water separately with downhole water sink wells[9]. Through the scholars' study, barrier layer technology is an useful and practical method to develop bottom water reservors, it is necessary to study the effect of barrier layers, which will reduce the production cost, optimize well spacing, delay the breakthrough and improve development effect[10]. This paper carries out a study on analyzing the effect of the barrier layer on the development of bottom water reservoirs, respectively, from three aspects of the barrier layer: the permeability, the size and the spatial distribution. It is helpful to provide some reference and supplement for the development of bottem water reservoirs.

\section{Establish a bottom water reservoir model}

Taking a reservoir with active bottom water in eastern China oilfield as the geological background, in this paper, a bottom water reservoir model was established by Schlumberger simulation software --Eclipse Front-Sim Section. To simplify the study, only one horizontal well was developed and a Carter aquifer acted as the bottom water in the geological model. The model's relative data and 3D map are shown in Table 1 and Fig.1.

\section{Design the streamline simulation program}

According to research objectives, the program is divided into two types: basic program and contrast program. The former emphasizes the difference of the development effect between the reservoirs with 
barier layer and without barier layer; the latter emphasizes the difference of barrier layer properties: different permeability, different size and different spatial distribution. Finaly, 7 programs are formed, including 22 cases in total, which will be descriped as follows.

Table 1 The relative parameter in streamline simulation model

\begin{tabular}{c|c|c|c|c|c|c}
\hline \multicolumn{3}{c|}{ Reservoir scope } & \multicolumn{4}{c}{ Reservoir property } \\
\hline Length/m & Width/m & Height/m & Porosity/\% & $\begin{array}{c}\text { Horizontal } \\
\text { permeability/mD }\end{array}$ & $\begin{array}{c}\text { Vertical } \\
\text { permeability/mD }\end{array}$ \\
\hline 600 & 300 & 15 & \multicolumn{2}{|c|}{19} & 500 & 300 \\
\hline \multicolumn{3}{c|}{ Model grid } & Aquifer property & \multicolumn{2}{c}{ horizontal well property } \\
\hline X & Y & $\mathrm{Z}$ & Radius/m & Thickness $/ \mathrm{m}$ & Wellbore length/m & Wellbore radius $/ \mathrm{m}$ \\
\hline 39 & 60 & 50 & 2000 & 100 & 200 & 0.1 \\
\hline
\end{tabular}

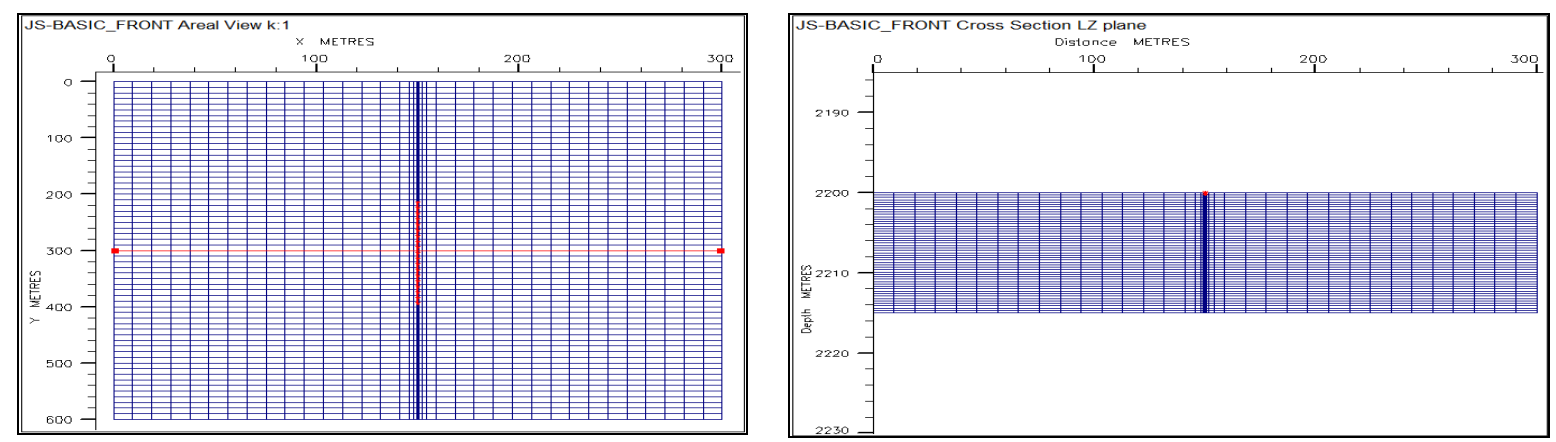

Fig. 1 The grid model 3D map

(1) Basic program — with and without barrier layer

Including two cases (Fig. 2), one without barrier layer (Case 0-1), the other with barrier layer (Case $0-2)$.

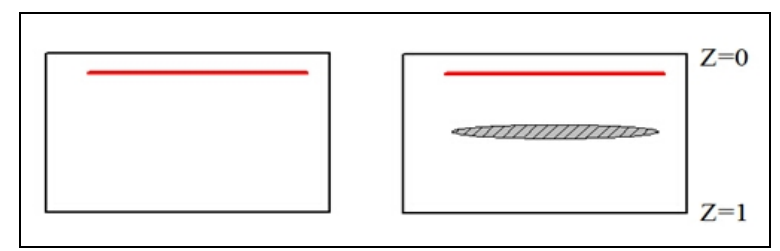

Fig. 2 The schematic diagram of barrier layer distribution

(2) Contrast program I-barrier layer with different permeability

Including five cases (Fig. 3), the permeability of barrier layer is, respectively, $0.1 \%, 0.5 \%, 1 \%, 5 \%$ and $10 \%$ of the reservoir permeability (Case 1-1, Case 1-2, Case 1-3, Case 1-4, Case 1-5).

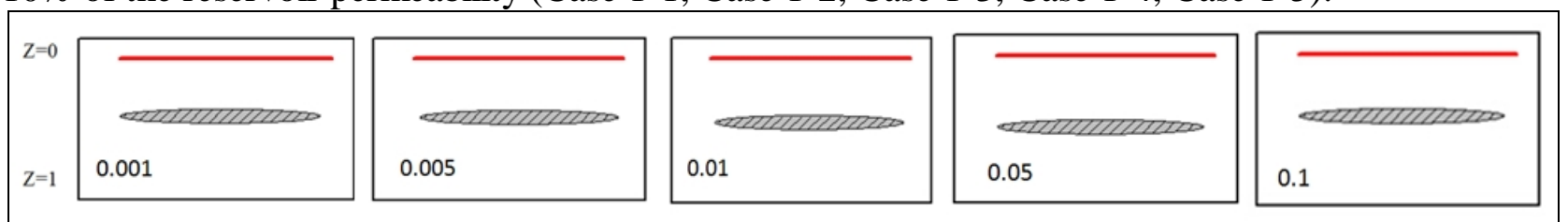

Fig. 3 The schematic diagram of barrier layer distribution

(3) Contrast program II-barrier layer with different size

Including five cases (Fig. 4), the length of barrier layer is, respectively, 10\%, 40\%, 70\%, 100\% and $200 \%$ of the length of horizontal well (Case 2-1, Case 2-2, Case 2-3, Case 2-4, Case 2-5).
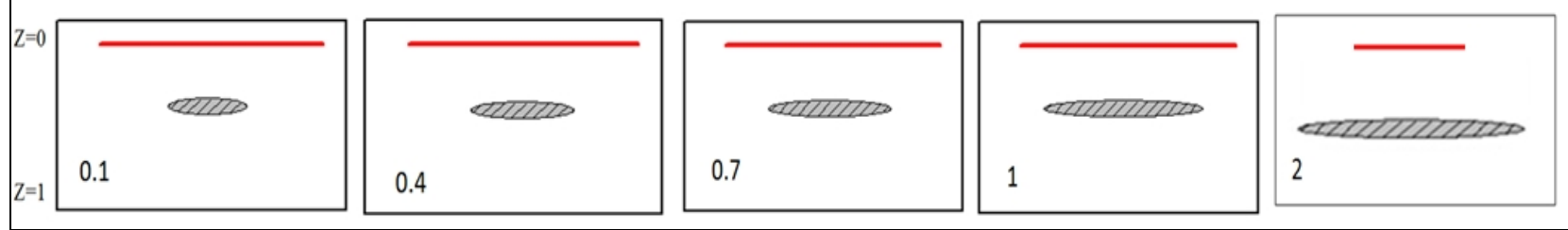

Fig. 4 The schematic diagram of barrier layer distribution 
(4) Contrast program III-barrier layer with different vertical position

Including four cases (Fig. 5), the vertical position of barrier layer is defined as $\mathrm{Z}$ value, in which 0 corresponds to the height of horizontal well and 1 corresponds to the height of WOC, respectively, 0.2, 0.4, 0.7 and 1 (Case 3-1, Case 3-2, Case 3-3, Case 3-4).

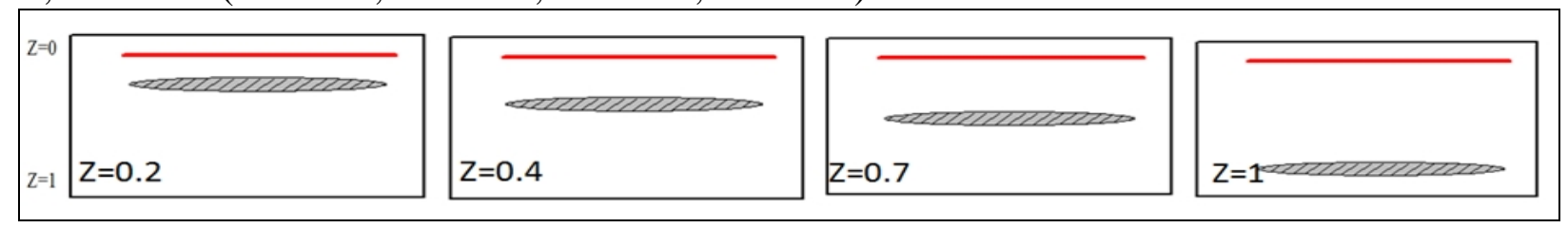

Fig. 5 The schematic diagram of barrier layer distribution

(5) Contrast program IV - barrier layer with different horizontal position

Including three cases (Fig. 6), the horizontal position of barrier layer $(Z=0.5)$ locates, respectively,on the left, in the middle and on the right (Case4-1, Case 4-2, Case 4-3).

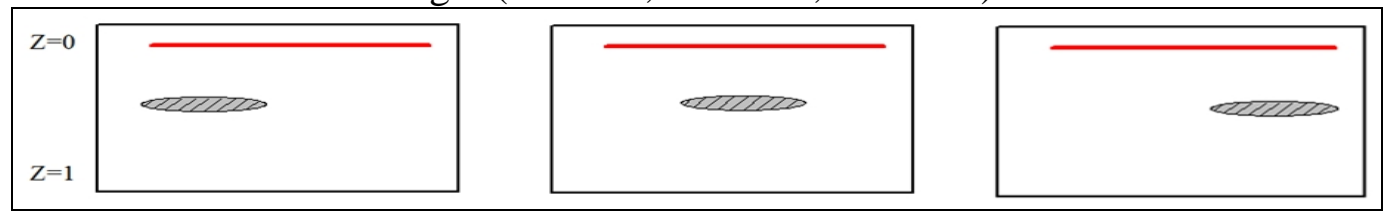

Fig. 6 The schematic diagram of barrier layer distribution

(6) Contrast program V-barrier layer with different spatial position

Including three cases (Fig. 7), with two barrier layers, the bottom barrier layer $(\mathrm{Z}=1)$ locates in the middle, however, the top barrier layer locates, respectively, on the left, in the middle and on the right (Case 5-1, Case 5-2, Case 5-3).

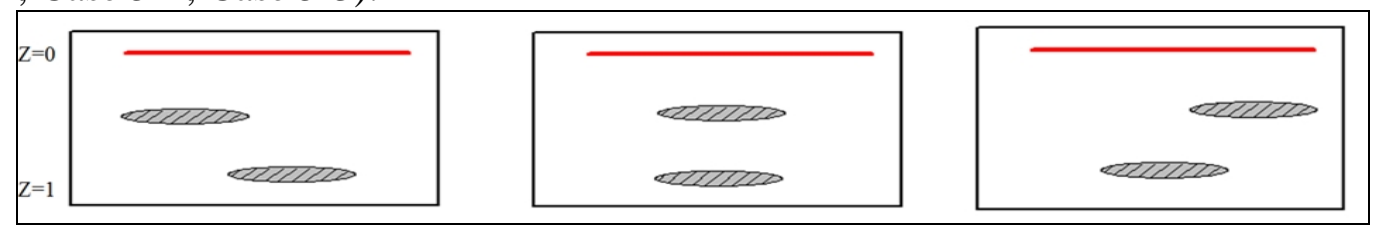

Fig. 7 The schematic diagram of barrier layer distribution

\section{The simulation results and qualitative analysis}

\section{The dynamic process of bottom water coning}

In streamline simulation method, it can show clearly the process of bottom water coning and the distribution of the streamline. Taking basic program as an example, in case $0-1$ with no barrier layer (Fig. 8), the bottom water inserts the reservoir gradually like a wedge with time going by and the oil-water interface rises to the horizontal well like a ridge on the whole. All streamlines distribute smoothly without obviously bending and converge at the bottom of the horizontal segment finally. In case 0-2 (Fig. 9), the oil-water interface rises less slowly than case 0-1 and there are two "spike-like" oil-water interfaces which advance up simultaneously. After reaching the height of barrier layer, the two water coning gather closer at the top of the barrier layer, thus a shape of a curtain is formed. At the same time, the streamlines bend near the barrier layer and bypass the barrier layer.

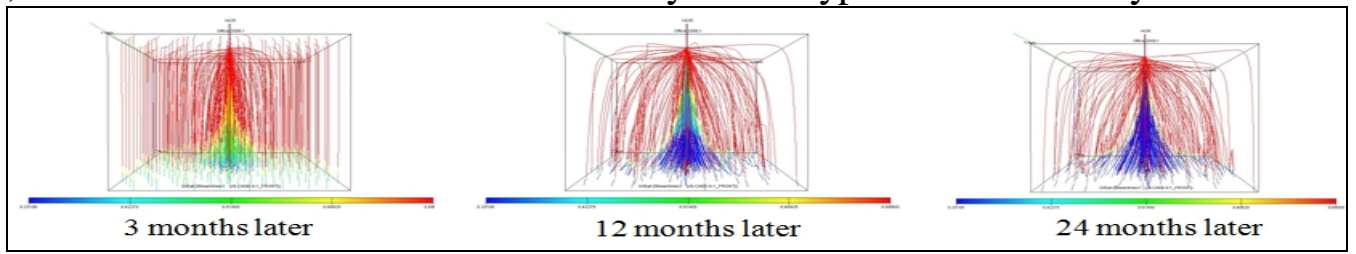

Fig. 8 The dynamic process of bottom water coning 


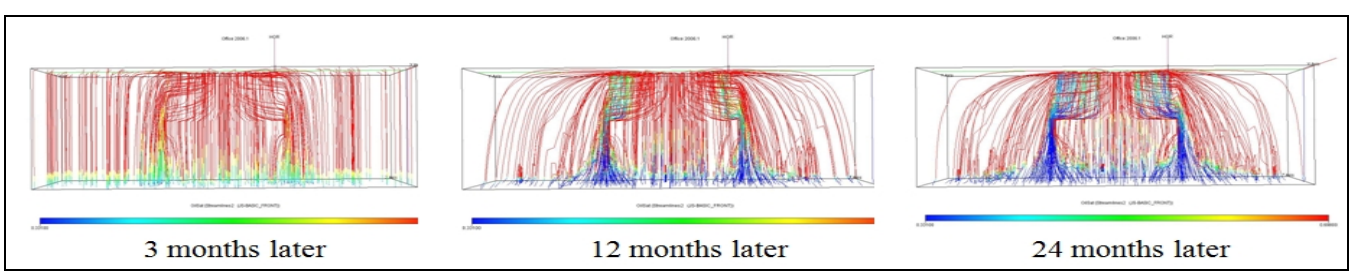

Fig. 9 The dynamic process of bottom water coning

\section{The qualitative analysis of the effect of the barrier layer}

\section{(1) Basic program — with and without barrier layer}

In Fig. 10, with time going on, the watercut of both cases increase quickly, but the case without barrier layer rises significantly faster than the case with barrier layer. Meanwhile, in Fig. 11, under the same watercut, the former's oil recovery is lower than the latter's. It indicates barrier layer plays an important role in the development of bottom water reservoirs and proper barrier layer distribution can control the bottom water coning, delay the breakthrough time and finally improve the oil recovery.

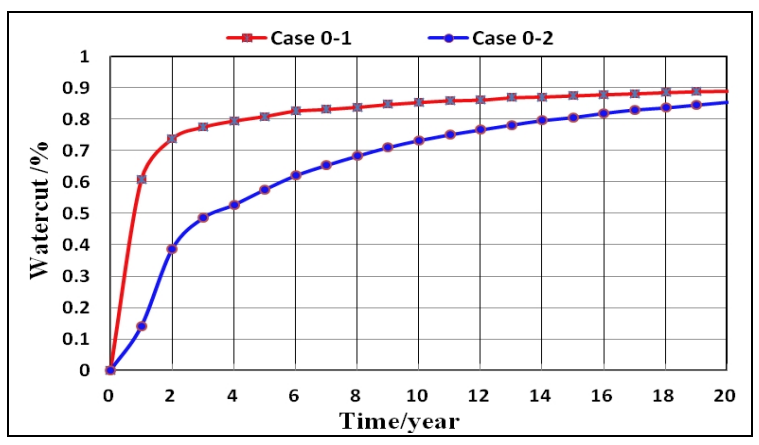

Fig. 10 The curve with watercut and time

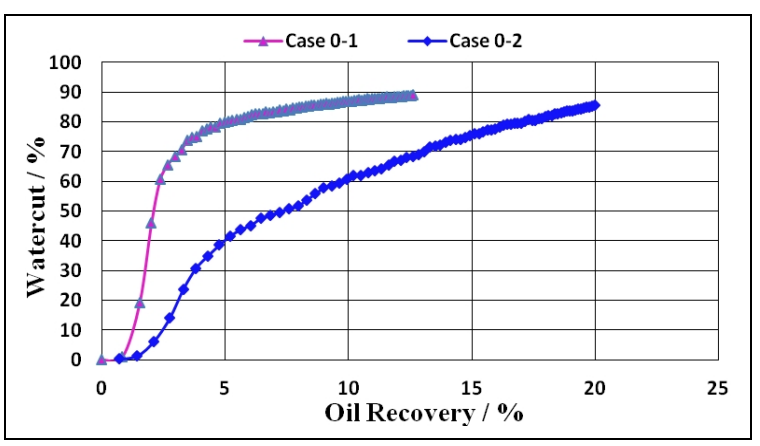

Fig. 11 The curve with oil recovery and watercut

\section{(2) Contrast program I-barrier layer with different permeability}

In Fig. 12, the watercut of five cases increase quickly at the first two years, then slow down and get closer and closer eventually. Meanwhile, in Fig. 13, when the permeability of the barrier layer gets closer to the reservoir's, the recovery become higher at the same watercut. It's advisable for the development of botttom water reservoirs to get the permeability of the barrier layer as low as possible.

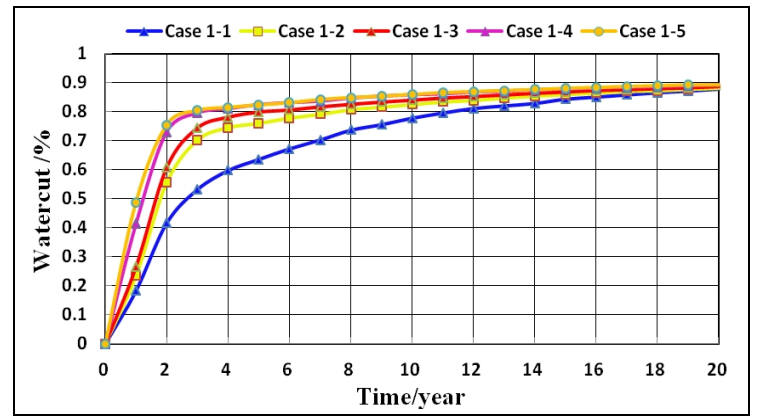

Fig. 12 The curve with watercut and time

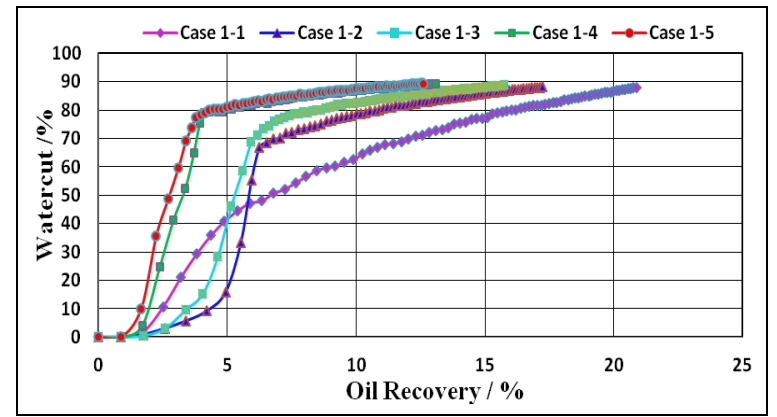

Fig. 13 The curve with oil recovery and watercut

\section{(3) Contrast program II-barrier layer with different size}

In Fig. 14, with the size of the barrier layer getting larger, the watercut increases slower and even when the size is large enough, there will be a no-water production period. It obviously reflects the larger size of the barrier layer can delay the breakthrough time. According to Fig. 15, it shows that the larger the size is, the higher the oil recovery is. For the reasons above, it's advisable for the development of botttom water reservoirs to get the size of the barrier layer as large as possible. 


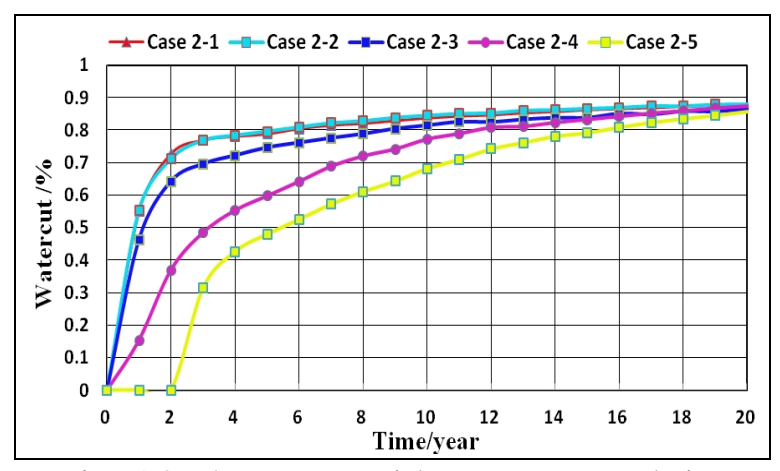

Fig. 14 The curve with watercut and time

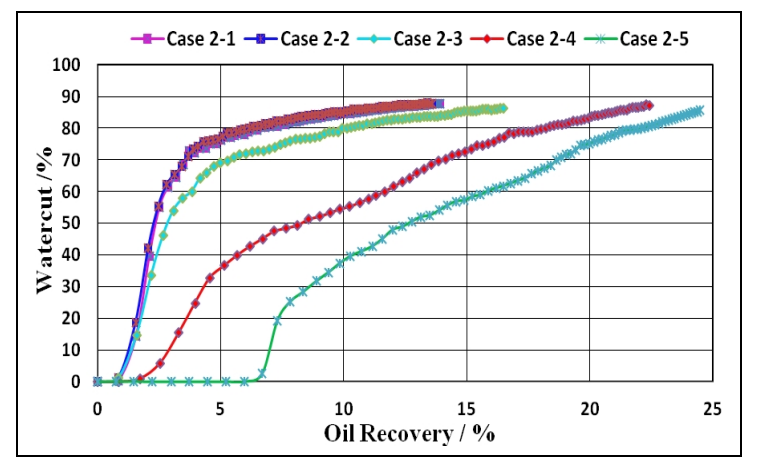

Fig. 15 The curve with oil recovery and watercut

\section{(4) Contrast program III-barrier layer with different vertical position}

According to Fig. 16 and Fig. 17, with the barrier layer getting closer to the oil-water interface, the watercut rises more quickly and the oil recovery is also lower at the same watercut. Therefore, it clearly proves that when the barrier layer is closer to the horizontal segment, it can be more beneficial to control the bottom water coning and improve the development effect.

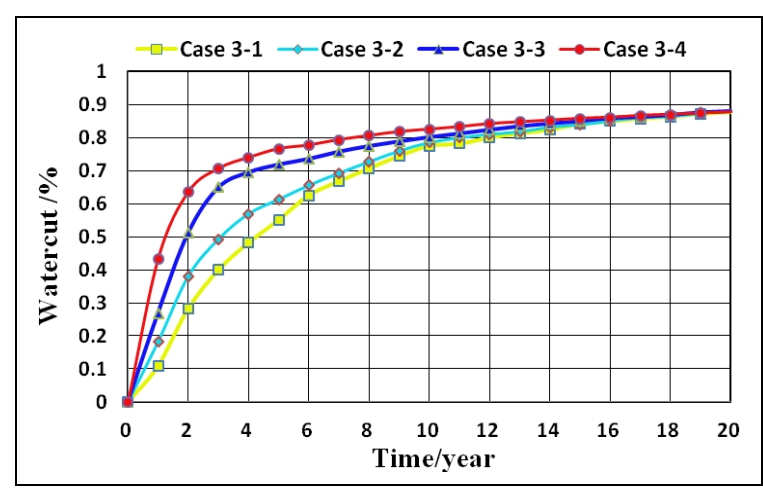

Fig. 16 The curve with watercut and time

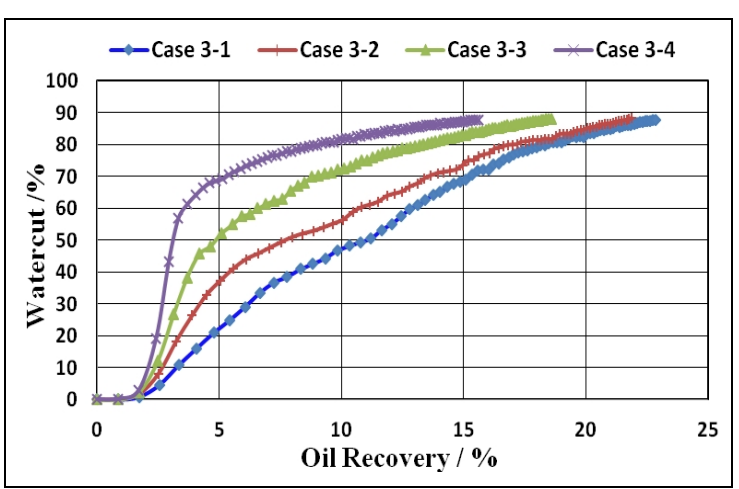

Fig. 17 The curve with oil recovery and watercut

\section{(5) Contrast program IV-barrier layer with different horizontal position}

In Fig.18 and Fig. 19, three cases' realtionship curves almost coincide, which indicates that under the same size and petrophysical property of the barrier layer, if the barrier layer just moves at the same height, there is no difference between the development offect of these cases.

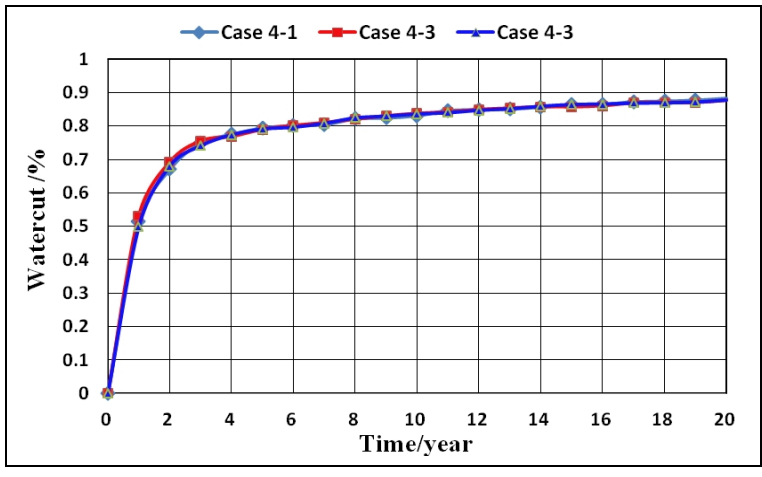

Fig. 18 The curve with watercut and time

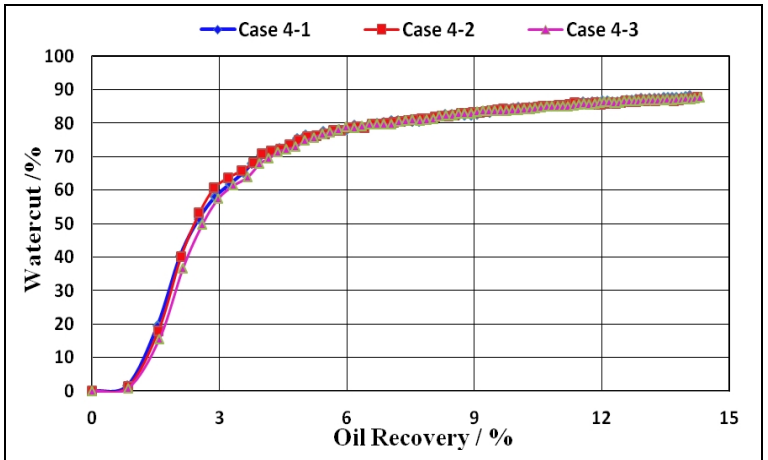

Fig. 19 The curve with oil recovery and watercut

\section{(6) Contrast program V-barrier layer with different spatial position}

From Fig. 20 and Fig. 21, the same behaviour as the contrast program above can be get. It further proves the above viewpiont: under the same size and petrophysical property of the barrier layer, if the barrier layer just move at the same height, there is no difference between the development effect of these cases. However, due to the existence of two layers, the development effect is better than the above three cases'. 


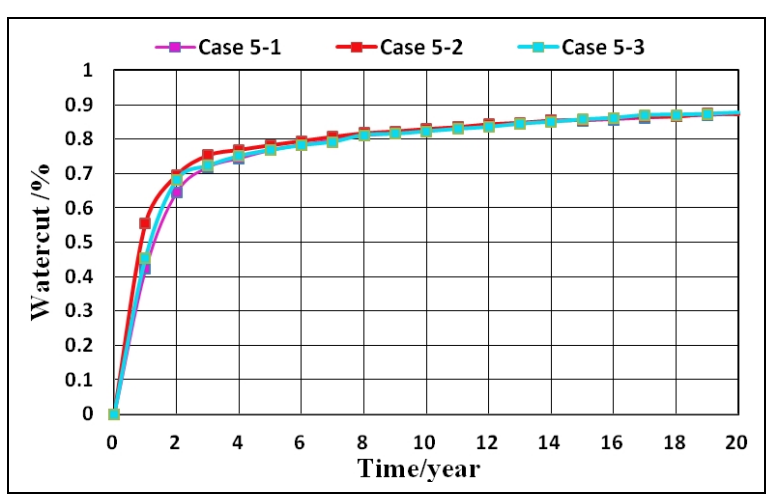

Fig. 20 The curve with watercut and time

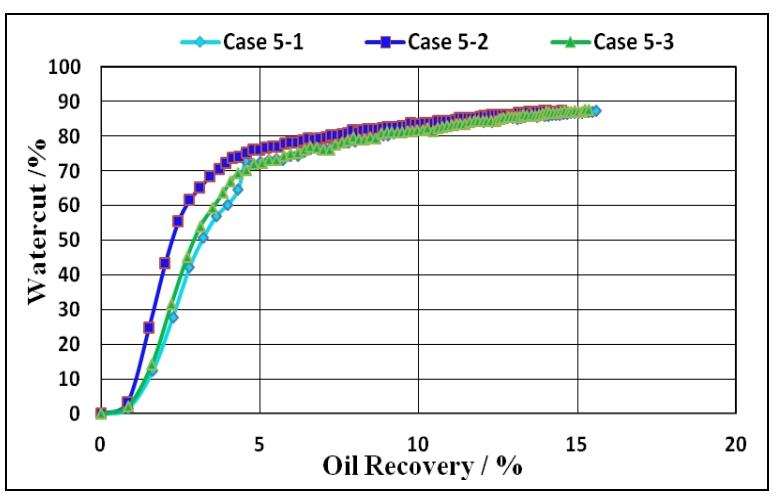

Fig. 21 The curve with oil recovery and watercut

\section{Conclusions}

a. The barrier layer plays an important role in the development of bottom water reservoirs and proper barrier layer distribution can control the bottom water coning, delay the breakthrough time and finally improve the oil recovery.

b. Under the same production condition, the lower permeability of the barrier layer, the larger size of the barrier layer and the closer distance between the barrier layer and the top of horizontal segment is, the better the development effect is.

c. When there are multiple barrier layers, the size and petrophysical property of the barrier layer is the same, if the barrier layer just moves at the same height, there is no difference between the development effect of these cases.

\section{Acknowledgments}

This article was supported by the National Natural Science Foundation of China, No.51204148.

\section{References}

[1] Su Kexin. Hubei: A Research of Improve the Bottom Water Coning Reservoir Development Effect Method. Yangtze University, China, 2012. (In Chinese).

[2] L. Jin, A.K.Wojtanowicz, R.G.Hughes. An Analytical Model for Water Coning Control Installation in Reservoir with Bottom Water. PETSOC Paper-2009-098.

[3] P. Permadi, T.Jayadi. An Improved Water Coning Calculation for Horizontal Wells. Paper SPE 133162, presented at 2010SPE/RO\&G Technical Conference helded in Moscow,Russia,26-28 (Oct.), 2010.

[4] Guo, B., Lee, R.L.H. A simple approach to optimization of completion interval in oil/water coning systems. SPE23994, SPE Reservoir Engineering Journal, 249-255(Nov.), 1993.

[5] Abass, H.H. Bass, D.M. The critical production rate in water coning system. SPE 17311, Permian Basin Oil and Gas Recovery Conference, Midland, TX. March 10-11,1988.

[6] Smith, C.R. Pirson, S.J. Water Coning Control in OilWells by Fluids Injection, SPE 613, SPEJ, Oct.1, 1963.

[7] Karp, J.C, Lowe, D.K., Marusov, N. Horizontal barriers for controlling water coning. JPT, 783790 (July), 1962.

[8] Chaperon, I. Theoretical study of coning toward horizontal and vertical wells in anisotropic formations: subcritical and critical rates. SPE 15377, 61st Annual Technical Conference and Exhibition, New Orleans, LA.Oct. 5 - 8, 1986. 
[9] Ould-amer, Y., Chikh, S., Naji, H. Attenuation of water coning using dual completion technology. Journal of Petroleum Science and Engineering 45 (2004), 109- 122.

[10] Zheng Haini, Li Xue, Li Gen, Zhu Meng. The Influencing Factors Analysis on Interlayer Controlling Bottom Water Coning in Sandstone Reservoirs [M]. Xinjiang Geology, Xinjiang, 2013: 44-49. (In Chinese) 